\title{
POSSIBLE “SiSTER" STONES OF THE HOPE DIAMOND
}

\author{
Scott D. Sucher, Stephen W. Attaway, Nancy L. Attaway, and Jeffrey E. Post
}

For more than a century, historians have debated the existence of "sister" stones to the Hope diamond, most notably the Brunswick Blue and the Pirie diamonds. The recent discovery of a lead cast of the French Blue, the Hope's precursor, has provided a more accurate model of that diamond, which disappeared in 1792. Computer models of the French Blue and its parent stone, the Tavernier Blue, were used to determine whether other diamonds might have been created when the Tavernier Blue was cut into the French Blue, or when the latter was cut into the Hope. The results show that it was not feasible for other significant diamonds to have been created during any recutting.

$\mathrm{T}$ he possibility that there might exist "sister" stones to the Hope diamond has long been the subject of speculation (see, e.g., Streeter, 1882; Bapst, 1889; Cattelle, 1911; Patch, 1976; and Balfour, 2009). Many believe that such diamonds could have been created when the Tavernier Blue was cut into the French Blue (at a loss of approximately 46 carats) in the 1670s, or when the French Blue was recut into the Hope (at a further loss of some 24 carats) in the late 18 th or early 19 th centuries. Streeter (1882) proposed that the $13^{3 / 4} \mathrm{ct}$ Brunswick Blue and the 11/4 ct Pirie diamonds (which he examined, though both are now long since lost from the public eye) were such

See end of article for About the Authors and Acknowledgments. Gems \& Gemology, Vol. 46, No. 1, pp. 28-35. byproducts and described in detail how they might have been created. Bapst (1889) also speculated on the connection with the Brunswick Blue. Morel (1988) pointed out errors in Streeter's methodology, rebutting any relationship between these two diamonds and the Hope. More recently, Attaway (2005) corroborated Morel's conclusion.

It is important to note that these earlier conclusions were based on the limited information and technology available at the time. The inherent constraints in modeling these historic diamonds required that assumptions be made about their physical attributes, leaving sufficient margin for error that sister stones might still have been possible (Kurin, 2006). The present study compares a specially created computer model of the Hope diamond with recent computer models of the French Blue (generated from a lead replica of this historical diamond; see Farges et al., 2008, 2009) and the Tavernier Blue (Sucher, 2009) to determine if other stones could have resulted from either recutting.

\section{MATERIALS AND METHODS}

Modeling. The French Blue model used in this study (figure 1) is the same one created from a lead cast of the French Blue, as reported by Farges et al. $(2008,2009)$. The Tavernier Blue model (figure 2), was developed by Sucher (2009) using this French Blue model and drawings published in Tavernier (1676), along with crystallographic information. We also needed an accurate three-dimensional model of the Hope diamond for comparison. Several techniques were considered for determining the Hope's facet angles and index settings, as well as measuring the diamond in three dimensions. Laser scanning, a touch probe, an optical comparator, and photomodelingwere all explored. Photomodeling was selected out of a need 

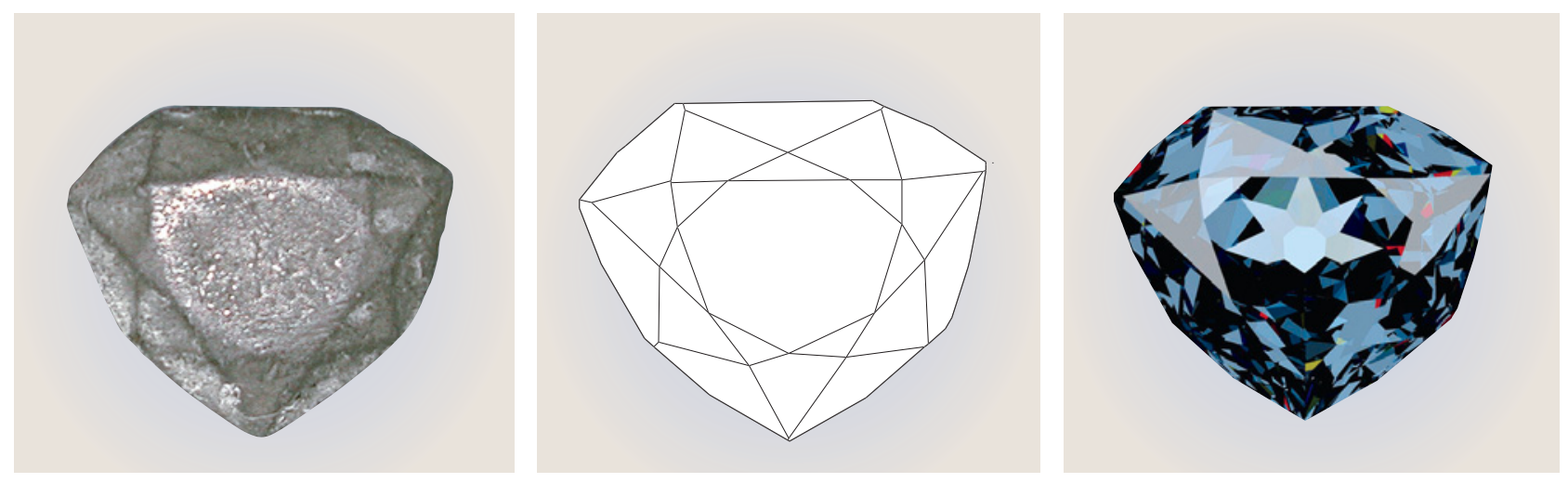

Figure 1. A recently discovered lead cast of the French Blue (left) has allowed more realistic modeling of the original diamond (a wireframe model, center; a photorealistic rendition, right) and, from this, more accurate determinations of how it and the Hope diamond were cut. Both models from Farges et al. (2008, 2009).

for security, cost-effectiveness, and speed. The last was especially important, as the Hope diamond can only be removed from its highly secure storage for a limited time. Many photographs can be taken in a short period and analyzed later, while the other methods would have required much longer periods out of the vault and thus greater security concerns.

Photomodeling is a process in which photographs of an object are taken from many different angles and analyzed using computer software. For this study, the Hope was unmounted and placed on a grid of $10 \mathrm{~mm}$ squares (figure 3) developed to provide a modeling reference while the stone was photographed from various angles. The Hope has a large culet that allows it to stand on its own without any supporting structure that could obscure important details from the camera. A series of dots were placed on the grid to maintain a position reference as the cardboard and stone were rotated, and the diamond was placed on the section of the grid framed by the dots. Top, bottom, and side photos were taken at every $45^{\circ}$ of rotation with the stone resting on both its culet and table facet. Additional photos were taken perpendicular to both the culet and the table facet for face-up and facedown perspectives.

A Nikon Coolpix 990 digital camera with 3.2 megapixel resolution was used for photography. We took approximately 150 photos of the unset diamond, 30 of which were chosen to characterize the stone. More than 300 points were identified to mark
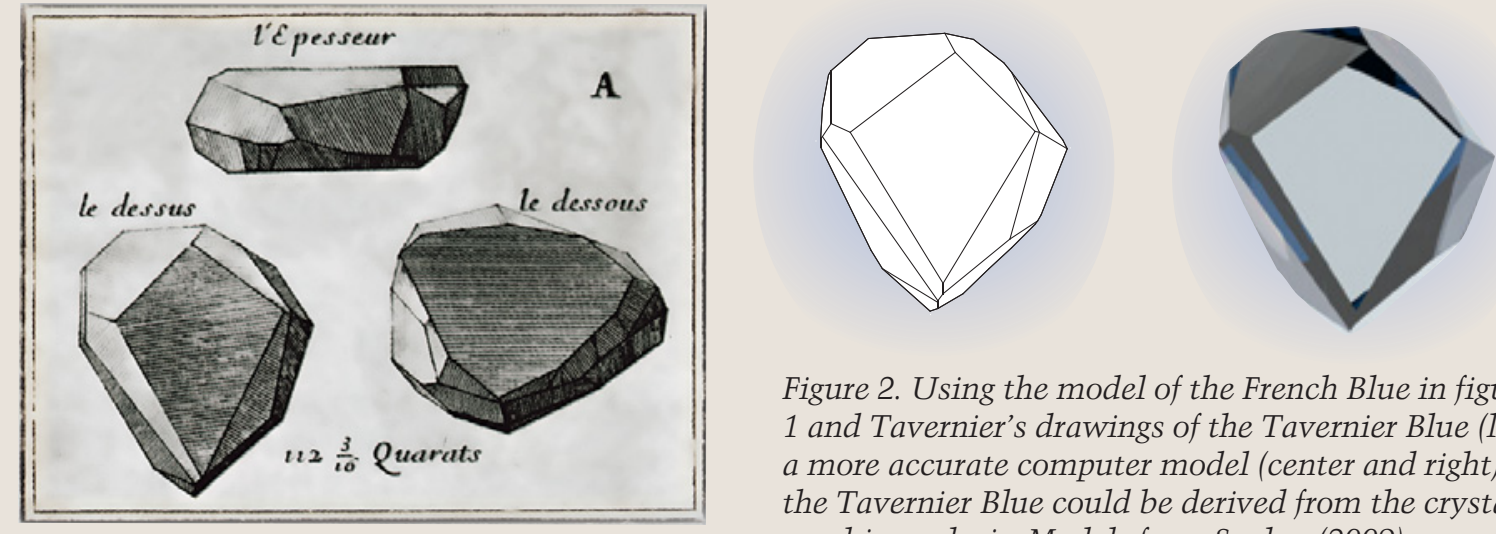

Figure 2. Using the model of the French Blue in figure 1 and Tavernier's drawings of the Tavernier Blue (left), a more accurate computer model (center and right) of the Tavernier Blue could be derived from the crystallographic analysis. Models from Sucher (2009). 


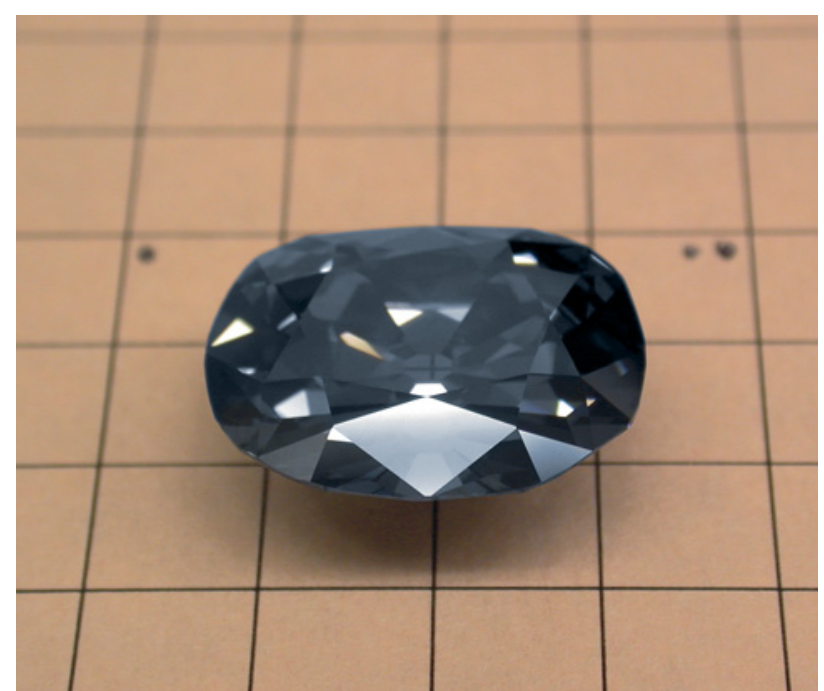

Figure 3. The Hope diamond was placed on a grid designed for photomodeling. The dots served as a fixed point of reference as the stone was rotated. Photo by S. D. Sucher.

the facet intersections. We labeled each facet junction with a unique identifier (figure 4) and plotted the location of all visible junctions in each picture. This process characterized the diamond from every angle to capture details concerning facet size, shape, and placement; girdle size and shape; and overall stone size and shape.

We used PhotoModeler software from Eos Systems to analyze the photos. This Windows-based program allows accurate measurements in three dimensions to be made from a series of photographs; it has been used for preparing forensic evidence in courts of law (Lynnerup and Vedel, 2005). After the software solved for the camera location, all points, lines, and surfaces were plotted in three-dimensional space. The index and angle were computed for each planar surface that defined a facet, and the information was then exported to GemCad to create a computer model.

Error Analysis. Accuracy of photo analysis is dependent on: (1) the quality and resolution of the camera, (2) the geometry of the camera positions, (3) the precision of the photo marking, and (4) how many points are visible in more than one photograph. The background grid in figure 3 provided a consistent geometric reference for accurate plotting, and also served as a check on the accuracy of the modeling solution. Accuracy was based on the number of pixels that spanned a given frame, so a comparison of grid size to frame size provided a measure of the available resolution. Photo dimensions were 2048 ×
1536 pixels, with the stone centered in the photo. (A raw format was used, with no correction for optical distortion.) For this resolution, an accuracy of about 1 part in 2,000 was achieved. Error analysis of the computer model showed a facet junction computed error ranging from 0.01 to $0.2 \mathrm{~mm}$.

In addition to labeling the facet junctions in PhotoModeler, we labeled the intersection points of the grid. These points had a known location and spacing that were used to take measurements between any two points on the diamond. After PhotoModeler calculated the simultaneous solutionof the least-squares fit for camera location, cam-

\section{NEED TO KNOW}

- Historians have long speculated about sister stones to the Hope diamond.

- An accurate computer model of the Hope diamond was created for comparison with recently developed models of its predecessors, the French Blue and Tavernier Blue diamonds.

- Comparison of this new model of the Hope with those of its predecessors demonstrated that there would have been insufficient material left overwhether cleaved or sawn — to create additional diamonds weighing $>1$ ct.

era lens parameters, and point locations, the solution was checked by comparing the solved points on the grid plane with the actual point spacing.

Figure 4. Facet junctions were labeled so their locations could be plotted during photo analysis. Photo by S. W. Attaway.

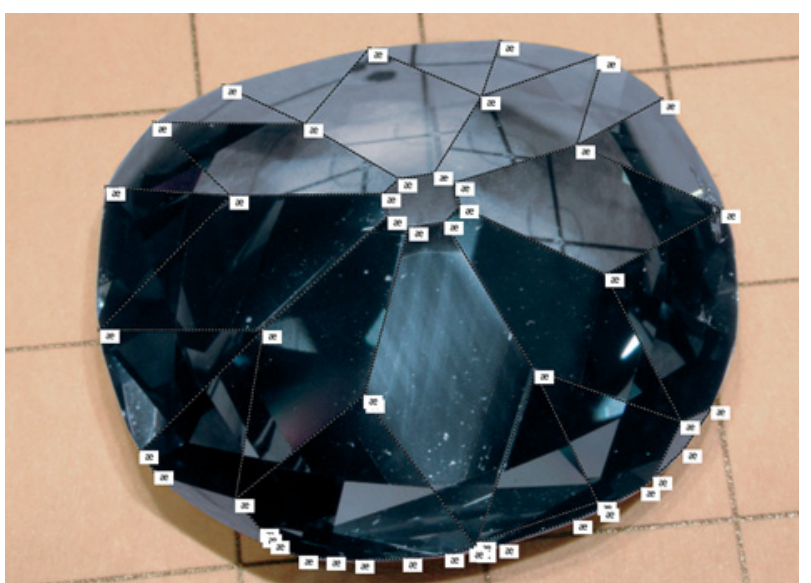



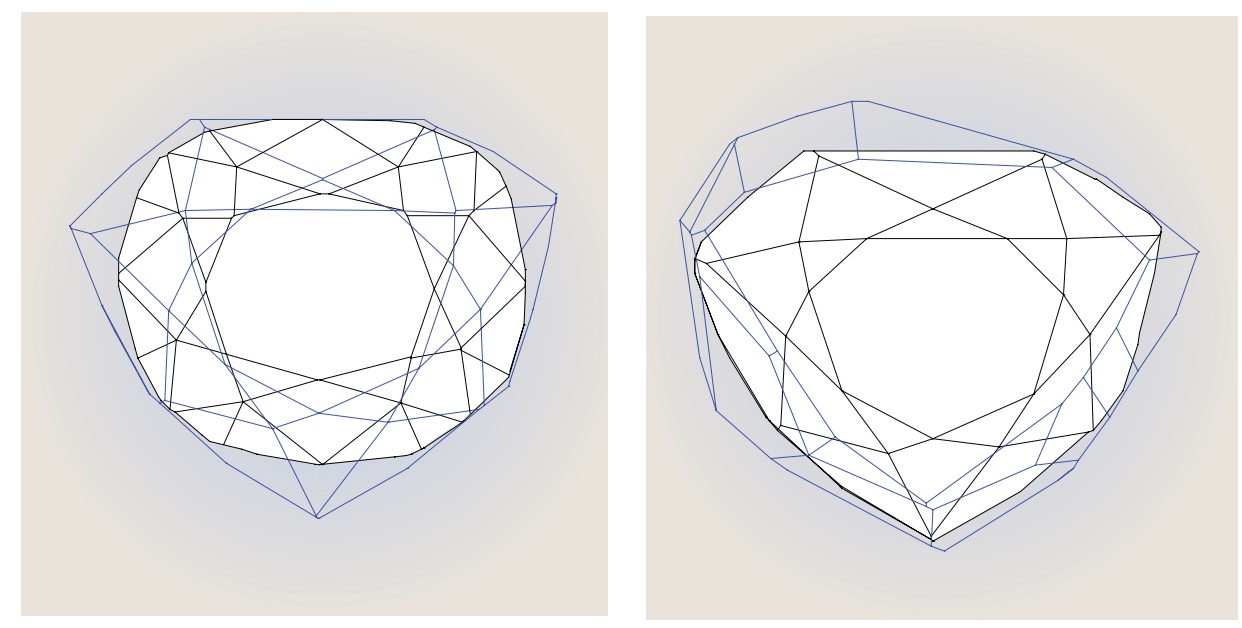

Figure 5. To evaluate the existence of facetable pieces from the Tavernier Blue when cut to become the French Blue-or from the French Blue when cut to become the Hope-the computer model of the Hope was placed inside the model of the French Blue (left), and that of the French Blue within the model of the Tavernier Blue (right).

Other errors to account for were parallax and lens distortion. PhotoModeler corrects for camera lens distortion by solving for focal length and other parameters. Telecentric lenses are frequently used for this process, inasmuch as they are designed so that an object's apparent size does not change as the distance between the lens and the object changes. Object size also remains unchanged if the camera view is slightly out of focus. PhotoModeler also corrects for the use of a non-telecentric lens; the only limitation is that the lens must be fixed at one zoom setting.

A 3D computer model was mathematically generated based on the best fit in three-dimensional space for the points marked on the photos. Once the residual error between the plotted points and the threedimensional solution was determined, we made position adjustments to selected points at the pixel level to further improve the model's accuracy. The model was considered accurate once the mean square error for all points was at a minimum.

Comparing the Models. The photo model of the Hope was placed inside the updated model of the French Blue in GemCad (figure 5, left) and rotated so that the smaller stone was completely encapsulated by the larger stone, as described in Farges et al. $(2008,2009)$. There was only one possible orientation, as the tolerances between the two were minimal (in some locations, they were only a fraction of a millimeter). Next, the French Blue model was placed inside the updated Tavernier Blue model by the same process (figure 5, right), as described in Sucher (2009). This process established the position of the "child" stone to its parent, allowing each pairing to be treated as a single unit for crystallographic alignment.
Aligning to an Octahedral Crystal. Using the data from Sucher (2009), the cleavage planes on the Tavernier Blue model were aligned to the cleavage faces $(\{111\}$ crystal faces) on an idealized model of a hexoctahedral diamond crystal (figure 6). We chose to use a simpler octahedral crystal model for this study, since the orientation of the Tavernier Blue had been established. With the Tavernier Blue model oriented to the octahedral crystal, we then oriented the Tavernier Blue/French Blue model combination. We selected one facet on the Tavernier Blue/octahedral model as a reference (totally arbitrary, as any facet would suffice). The GemCad file

Figure 6. To identify cleavage planes, the Tavernier Blue model was placed inside a model of an idealized octahedral diamond crystal. The top crystal face and table of the Tavernier Blue are "face-up" and aligned with a $\{111\}$ face.

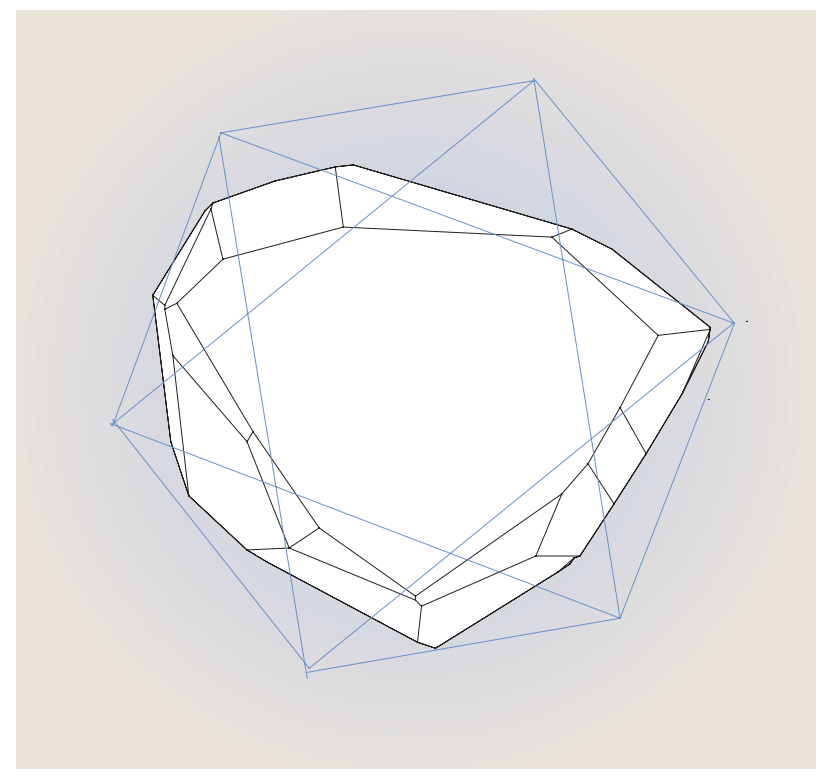


with the Tavernier Blue/French Blue combination was opened, and this composite image was rotated until the reference facet on the Tavernier Blue in each file had the same angle and index settings (as explained in Sucher et al., 2008). The French Blue/Hope model was aligned in similar fashion using a reference facet from the French Blue. All three diamond models were now aligned to each other and the octahedral crystal, with the cleavage planes in any of the diamonds aligned to each octahedral crystal face.

Analyzing the Models. Once the models were aligned to the octahedral crystal, the cleavages in each stone could be established by referring to the facet settings for the $\{111\}$ octahedral crystal faces. In digitally cleaving the Tavernier Blue in GemCad, these settings were used to remove pieces from the model (as described in Sucher, 2008), with the depth of the cut controlled so that nothing was removed from the French Blue model during the process. Each cleaved fragment from the model was saved as a preform, then analyzed in the GemCad Preform/Edit mode for dimension, weight, and shape. The same process was used to determine the possible cleavages when the French Blue was cut into the Hope. The result of any sawing operation was similarly analyzed.

\section{RESULTS AND DISCUSSION}

The Hope Model. The dimensions for the Hope diamond computer model, compared to the actual diamond (as determined by the Smithsonian) are shown in table 1. Dimensional differences between actual measurements and model measurements are artifacts of the measuring process.

Cleaving. There are six possible cleavage planes for a diamond crystal (three on top and three on the bottom) when a cleavage face is oriented "face-up." Only the 120 cleavage plane on the Tavernier Blue digitally removed material of a size that could have been recut (figure 7). This piece weighed $2.2 \mathrm{ct}$; it was $3.02 \mathrm{~mm}$ in depth and irregularly shaped. The cleavage planes on the bottom of the stone were parallel to the lines on the other side. As evident from the drawings, it would not have been possible to remove any material of significant size from any other cleavage direction. The cutter of the Hope maintained even closer tolerances to the French Blue. Of the six possible cleavages, the only piece that could have been digitally cleaved was from the
TABLE 1. Measurements of the Hope diamond and its computer model.

\begin{tabular}{lcccc}
\hline & $\begin{array}{c}\text { Weight } \\
(\mathrm{ct})\end{array}$ & $\begin{array}{c}\text { Length } \\
(\mathrm{mm})\end{array}$ & $\begin{array}{c}\text { Width } \\
(\mathrm{mm})\end{array}$ & $\begin{array}{c}\text { Depth } \\
(\mathrm{mm})\end{array}$ \\
\hline $\begin{array}{l}\text { Actual Hope } \\
\text { diamond }\end{array}$ & 45.52 & 25.60 & 21.78 & 12.0 \\
Hope model $^{\mathrm{b}}$ & 45.52 & 25.72 & 21.86 & 11.95 \\
\hline
\end{tabular}

a Measurements taken in February 2004 by author JEP.

${ }^{b}$ Based on photomodeling for the present study.

pavilion at the 120 index (figure 8). This piece weighed $0.95 \mathrm{ct}$ and was just $1.14 \mathrm{~mm}$ thick. No stones could have been created from a piece of this depth, so as a matter of practicality, no pieces of the French Blue would have been removed by cleaving.

Theoretically, then, the only chance of a sister stone being created from a cleavage piece comes from the $2.2 \mathrm{ct}$ portion of the Tavernier Blue. Again, this is highly unlikely. Ascertaining the cleavage planes in a cut stone is extremely difficult, as crystallographic information contained on the surface of the original crystal is lost. Although we now know that the largest facets on the Tavernier Blue were $\{111\}$ crystal faces, Jean Pitau (the cutter of the French Blue) would have needed to make an educated guess as to whether they were cubic, dodecahedral, or octahedral. He would have had no way of accurately correlating facets to crystal faces, making the process of locating cleavage planes extremely problematic. This would increase the level of risk during the cleaving operation, as a bad guess might destroy a 115 ct piece of diamond to salvage (at best) $2.2 \mathrm{ct}$ of rough.

Sawing. Could the Tavernier Blue or the French Blue have been sawn? De Boodt (1604) mentioned the use of a bow saw to cut gemstones (figure 9). He used the phrase "crassiries laminae secans lappides" (p. 77), which translates to a "thin sheet of metal for cutting gems." A mixture of water and grit would be constantly applied as the saw was drawn back and forth, until the stone was completely sawn through. This passage was written decades before the Tavernier Blue was cut (1671-1673), so we know that Pitau had access to stone sawing technology (though not necessarily diamond sawing technology). De Boodt specifically mentioned smiri as grit for cutting large ornamental stones such as jasper and marble. He did not indicate its use for cutting diamonds, or that diamond grit was ever used to cut any stone. Nor did he refer to cutting diamonds with such equipment, making it highly doubtful that it was used for this purpose. 


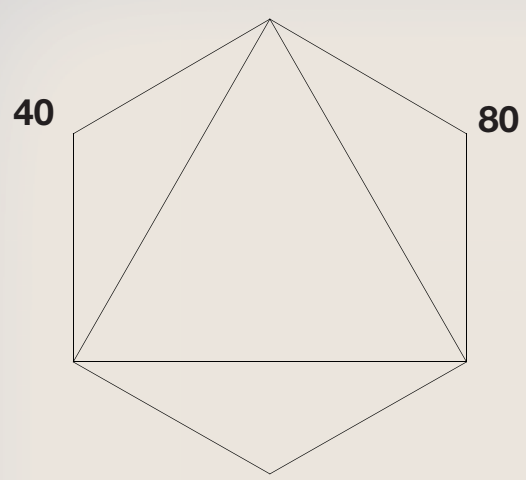

120

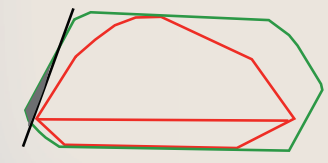

40
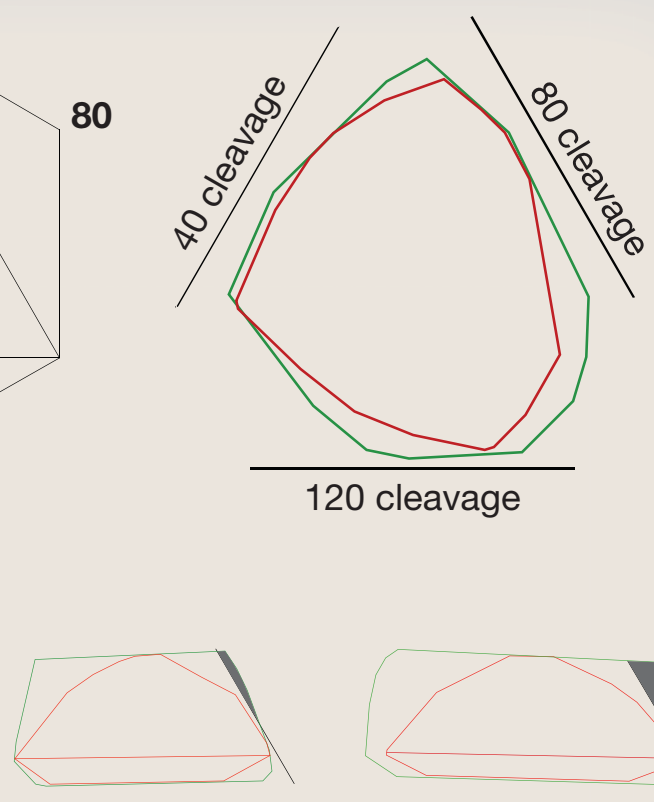

80

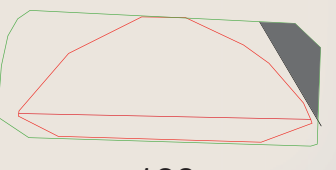

120
Figure 7. These outlines of the Tavernier Blue upper view (green) and the French Blue (red) show the orientation of cleavage planes (top right). Index settings are on the perimeter. Only one of the cleavage planes, from the 120 index setting, could have produced a cuttable fragment (bottom right). The side views oriented at the 40, 80, and 120 index settings at an angle of $70.5^{\circ}$ show that there are no significant cleavage pieces at the 40 and 80 settings.
Dr. Nebenjab Grepp (Grepp, 1681, pp. 282-283) mentioned the use of a saw for diamonds made of "a very small iron Wyre, and having daubed it with Oil and Powder of Diamonds; draw it upon the Diamond, by a Tool, to and fro like a Saw." This is the earliest known documentation of a wire saw used for diamond sawing. But does it mean that this technology existed in 1671, 10 years earlier, when Pitau created the French Blue? This can only be a point of conjecture until other evidence is discovered.

Even assuming diamond sawing was practiced in 1671, the largest piece of the Tavernier Blue that theoretically could have been removed would have been $6.6 \mathrm{~mm}$ in depth, yielding a $5.3 \mathrm{ct}$ piece (figure 10). This conclusively eliminates the possibility of the Brunswick Blue as a sister stone. Two other fragments could have resulted, but they would have been only $4 \mathrm{~mm}$ in depth and steeply tapered with no reasonably expected yield. The thickest piece of the French Blue theoretically removed by sawing (the very tip) would have resulted in a 2.8-mm-deep piece weighing 3.46 ct (figure 11). Thus, two pieces of both the Tavernier Blue and the French Blue could-theoretically-have been removed by sawing. But were any of these pieces actually removed, even if the technology existed? More than likely not, for the following reasons:
1. Grepp's statement indicates a very simple process. Would this process have been sufficiently sophisticated to saw off the tip of the Tavernier Blue, and accurate enough so that any part of the future French Blue was not removed? This is certainly not indicated.

2. Kerf (width of cut) losses must be considered. Grepp does not provide a wire diameter, but there is invariably some loss of material as the wire is drawn through the diamond. The cut must be wider than the wire diameter, as Grepp infers the saw is handheld. If the width of the cut was just $2 \mathrm{~mm}$, resulting in a sawn piece $4.6 \mathrm{~mm}$ thick, this reduces the largest sawn piece of the Tavernier Blue to $1.5 \mathrm{ct}$, which likely eliminates the $1 \frac{1}{4}$ ct Pirie as well. Kerf considerations completely preclude getting any usable pieces when the French Blue was cut into the Hope.

3. Starting a cut on the sloped polished surface of the Tavernier Blue would have been extremely difficult. The cutter would have wanted to err on the side of caution and move the blade away from the planned bodies of the French Blue or Hope, further reducing the thickness and weight of the sawn piece. 


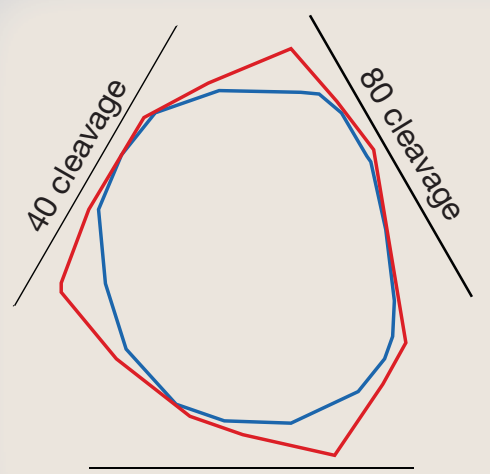

120 cleavage

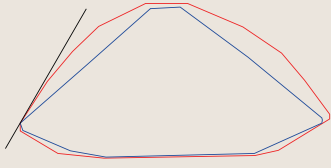

40

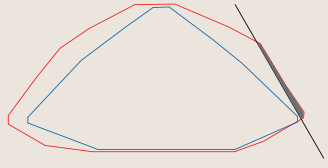

80

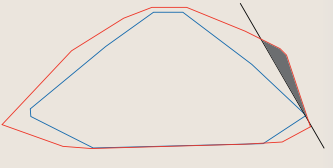

120

Figure 8. Like figure 7, these outlines of the French Blue (red) and Hope (blue) show the orientation of cleavage planes. Only a tiny fragment could have been cleaved from the 120 index (far right).

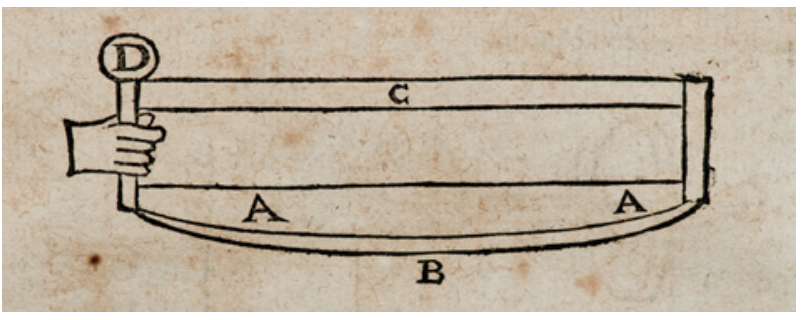

Figure 9. De Boodt's 1604 drawing shows the bow saw he described for cutting gemstones. It is doubtful this could have been used to saw diamonds.

4. Maintaining a cut at the precise angle needed and following the proper track would have been difficult. Neither De Boodt nor Grepp mentions the use of any guides.

5. Perhaps most importantly, Jean Pitau's charter for recutting the Tavernier Blue was to create a stone of regal size and appearance (Farges et al., 2008,2009 |, not maximize yield. It is difficult to imagine King Louis caring about preserving such small fragments, and it would of course have been a crime for Pitau to have kept any pieces without the king's permission. Thus, it is doubtful Pitau would want to take the risk when a mistake could literally have been fatal.

In summary, it is highly unlikely that either the Tavernier Blue or the French Blue was cleaved, due to the difficulty of locating the cleavage planes and the inherent danger of destroying the parent stone. Sawing the two diamonds is historically and technically questionable. Even if sawing was possible, the existence of residual fragments of any significant size is not likely. The most reasonable conclusion is that both diamonds were reduced by grinding alone.

Figure 10. Under ideal theoretical circumstances, a 5.3 ct piece could have been sawn from the Tavernier Blue. Shown here is the model with the cutting plane viewed edge-on (left). The possible sawn piece is in black. The center model shows the same view rotated $80^{\circ}$. At right is the model with the sawn piece removed, showing the French Blue model inside.
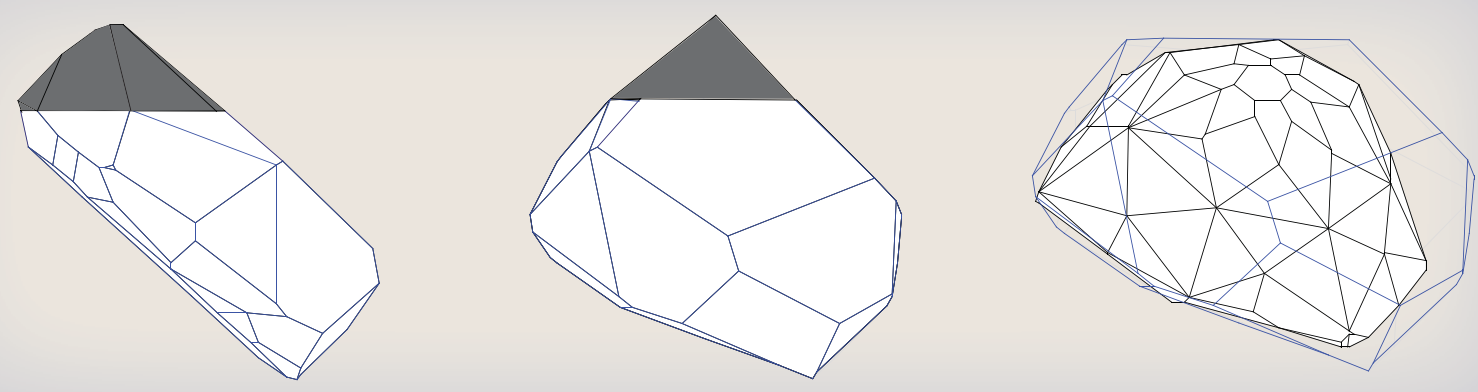


\section{CONCLUSIONS}

The possibility that the $13 \% / 4$ ct Brunswick Blue and

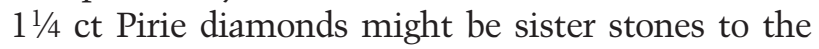
Hope has been a somewhat romantic notion since Streeter's proposal in the late 19th century. Previous modeling efforts to address this issue were constrained by the limited information available on both the Tavernier Blue and French Blue diamonds, with historical line drawings the only viable references to their appearance. This led to uncertainty and error in modeling these stones.

The recent discovery of a lead cast of the French Blue at the Muséum National d'Histoire Naturelle in Paris provided the best possible computer model of this diamond. It was subsequently used to refine the latest Tavernier Blue model, and a computer model of the Hope was generated for this study by photomodeling. When the three diamond models were compared and analyzed, it was evident that sister stones could not have been created. Cleavage would have been too risky for such a minimal return. Pieces of the size needed to create the

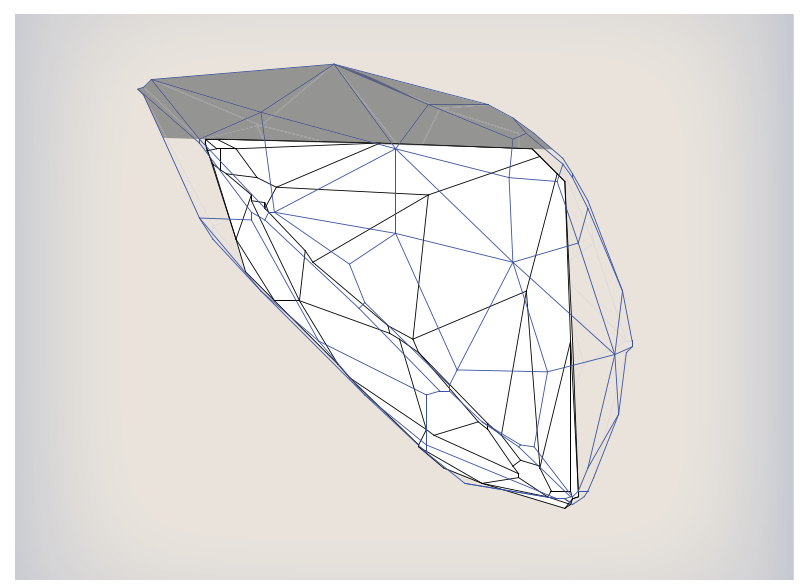

Figure 11. It is theoretically possible that a $3.46 \mathrm{ct}$ piece (shaded area) could have been sawn from the French Blue along one of the pavilion facets.

Brunswick Blue are physically impossible, and while creating the Pirie would have theoretically been possible from a sawn piece, it would have been impractical, even if the technology existed. This corroborates earlier assertions by Morel and Attaway that no sister stones to the Hope resulted from the cutting of the Tavernier Blue or French Blue diamonds.
ABOUT THE AUTHORS

Mr. Sucher (scott@museumdiamonds.com) is principal of The Stonecutter in Tijeras, New Mexico. Dr. and Mrs. Attaway are the principals of High Country Gems in Tijeras. Dr. Post is curator of the National Gem and Mineral Collection at the Smithsonian Institution's National Museum of Natural History in Washington, DC.

\section{ACKNOWLEDGMENTS}

The authors thank Jeff Kaufman of the Discovery Channel for making this project possible. Dr. François Farges, professor of mineralogy and curator of minerals and gems at the Muséum National d'Histoire Naturelle (MNHN) in Paris, provided insights regarding the cutting of the French Blue. They also thank Karen Sucher for her support and advice on stone cutting. Ms. Julianne Terrill of Rio Grande High School, Albuquerque, kindly translated Anselmus de Boodt's Latin text.

\section{REFERENCES}

Attaway N. (2005) The French connection. Lapidary Journal, June, pp. 24-28.

Balfour I. (2009) Famous Diamonds, 5th ed. Antique Collectors' Club, Woodbridge, Suffolk, UK.

Bapst C.G. (1889) Histoire des Joyaux de la Couronne de France [History of the French Crown Jewels]. Hachette, Paris.

Bion J.-M., Delattre F.-P., Christin C.-G.-F. (1791) Inventaire des diamants de la couronne, perles, pierreries, tableaux, pierres gravées, et autres monumens des arts \& des sciences existans au garde-meuble (...) [Inventory of diamonds of the crown, pearls, precious gems, paintings, engraved stones, and other monuments of arts \& sciences in the royal storehouse]. Imprimerie Nationale, Paris.

de Boote A. (1604) Gemmarum et Lapidum Historia. Joannis Maire, Leiden.

Cattelle W. (1911) The Diamond. John Lane Co., New York.

Farges F., Sucher S., Horovitz H., Fourcault J.-M. (2008) Deux découvertes majeures autour du "diamant bleu de la Couronne" [Two major discoveries about the "Blue Diamond of the Crown"]. Revue de Gemmologie, No. 165, pp. 18-24.

Farges F., Sucher S., Horovitz H., Fourcault J.-M. (2009) The French Blue and the Hope: New data from the discovery of a historical lead cast. $G \uplus G$, Vol. 45, No. 1, pp. 4-19.

Grepp N. (1681) Catalogue and Description of the Natural and Artificial Rarities Belonging to the Royal Society and Preserved at Gresham College. W. Rawlins, London.

Kurin R. (2006) Hope Diamond: The Legendary History of a Cursed Gem. Harper Collins, New York.

Lynnerup N., Vedel J. (2005) Person identification by gait analysis and photogrammetry. Journal of Forensic Sciences, Vol. 50, No. 1, pp. 112-118.

Morel B. (1988) The French Crown Jewels. Fonds Mercator, Antwerp.

Patch S.S. (1976) Blue Mystery: The Story of the Hope Diamond. Smithsonian Institution Press, Washington, DC.

Streeter E.W. (1882) The Great Diamonds of the World. George Bell and Sons, London.

Sucher S., Carriere D. (2008) The use of laser and X-ray scanning to create a model of the historic Koh-i-Noor diamond. $G \uplus G$, Vol. 44, No. 2, pp. 124-141.

Sucher S.D. (2009) A crystallographic analysis of the Tavernier Blue diamond. $G \uplus G$, Vol. 45, No. 3, pp. 178-185.

Tavernier J.B. (1682) Travels in India, Vol. II. Translated by V. Ball (1889), Macmillan and Co., London. 